\title{
Impressions of a Boreal Owl
}

by Lawrence R. Ostoforoff, Saskatchewan Museum of Natural History
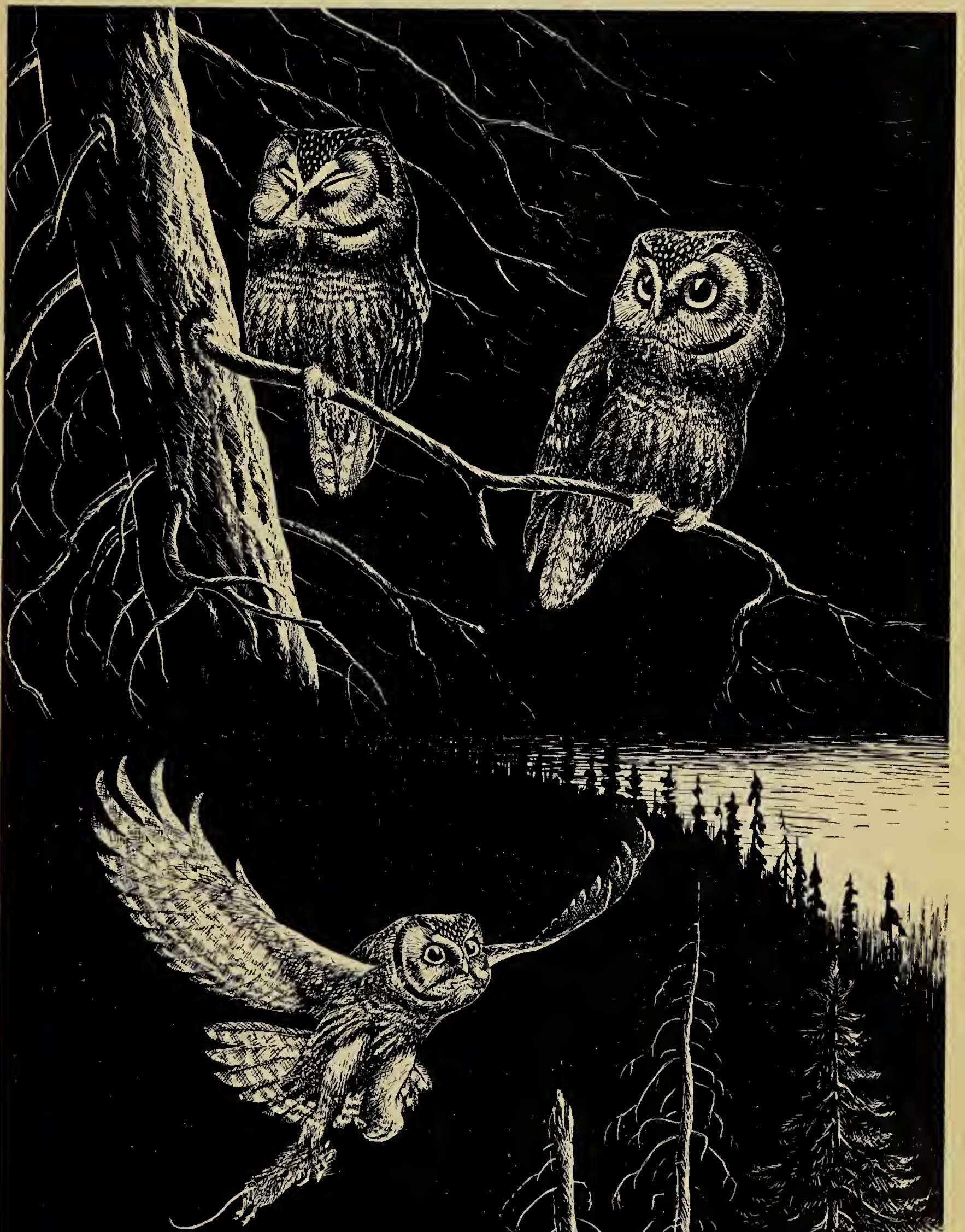

L. R. Ostefereff

$-1960-$

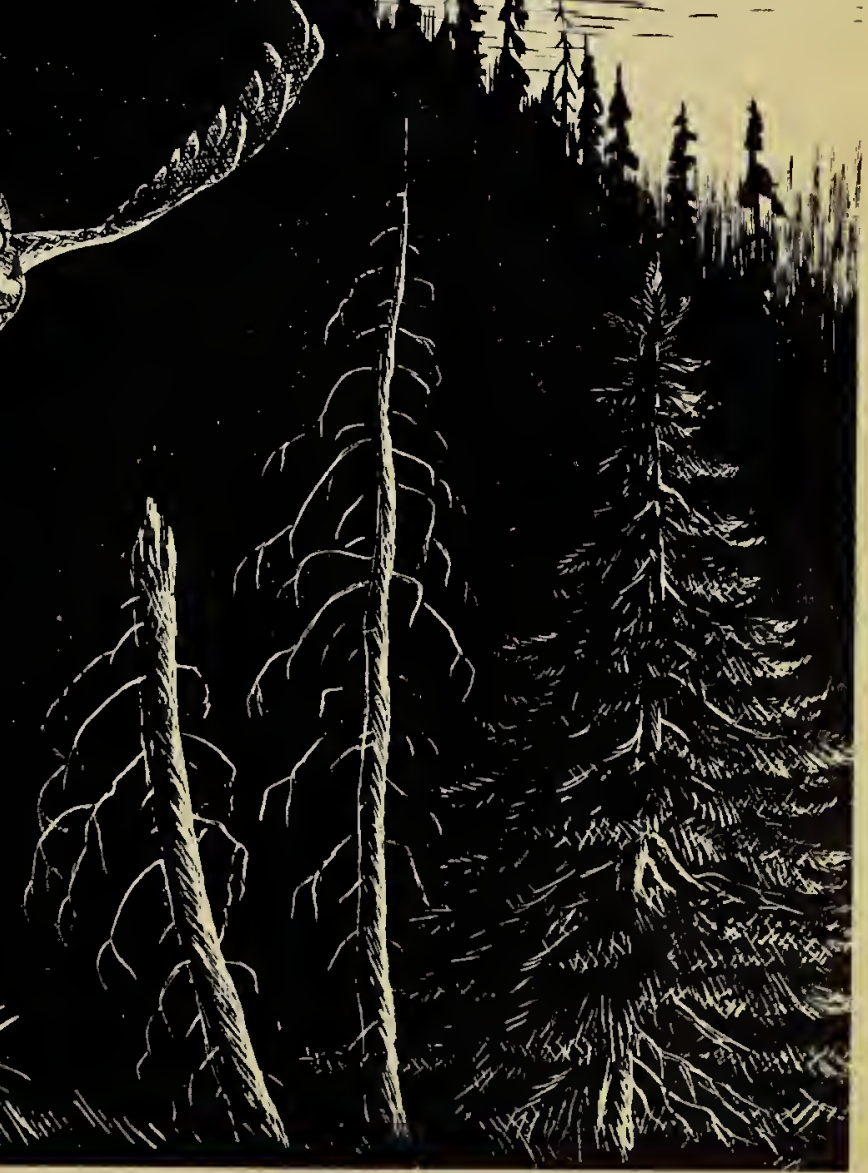


was always hit with full force, the momentum of the owl's plunge sending the bird and its prey skidding several feet across the floor.

It is brea'th-taking to imagine the force with which a Great Horned Owl must strike its prey.

The owl always seized the mouse just behind the head. Holding the struggling prey firmly, the owl would kill it with one quick bite into the back of its head. Then the owl would fly up to its perch carrying the mouse clenched in one foot. Invariably it first ate the head and organs of the thorax. Often the owl would then tuck the carcass into a corner near its perch, coming back tio dine on the remainder about a half hour later.

The feet of the Boreal Owl seemed to me to be very dexterous. When eating small pieces of food her feet were used like hands to bring up morsels to her mouth in a very dainty manner. She usually ate with closed eyes, taking her time and seeming to enjoy each bit of food. Very often when the meat was sinewy or hard, she would first tenderize it by rapidly nibbling at it with her beak.
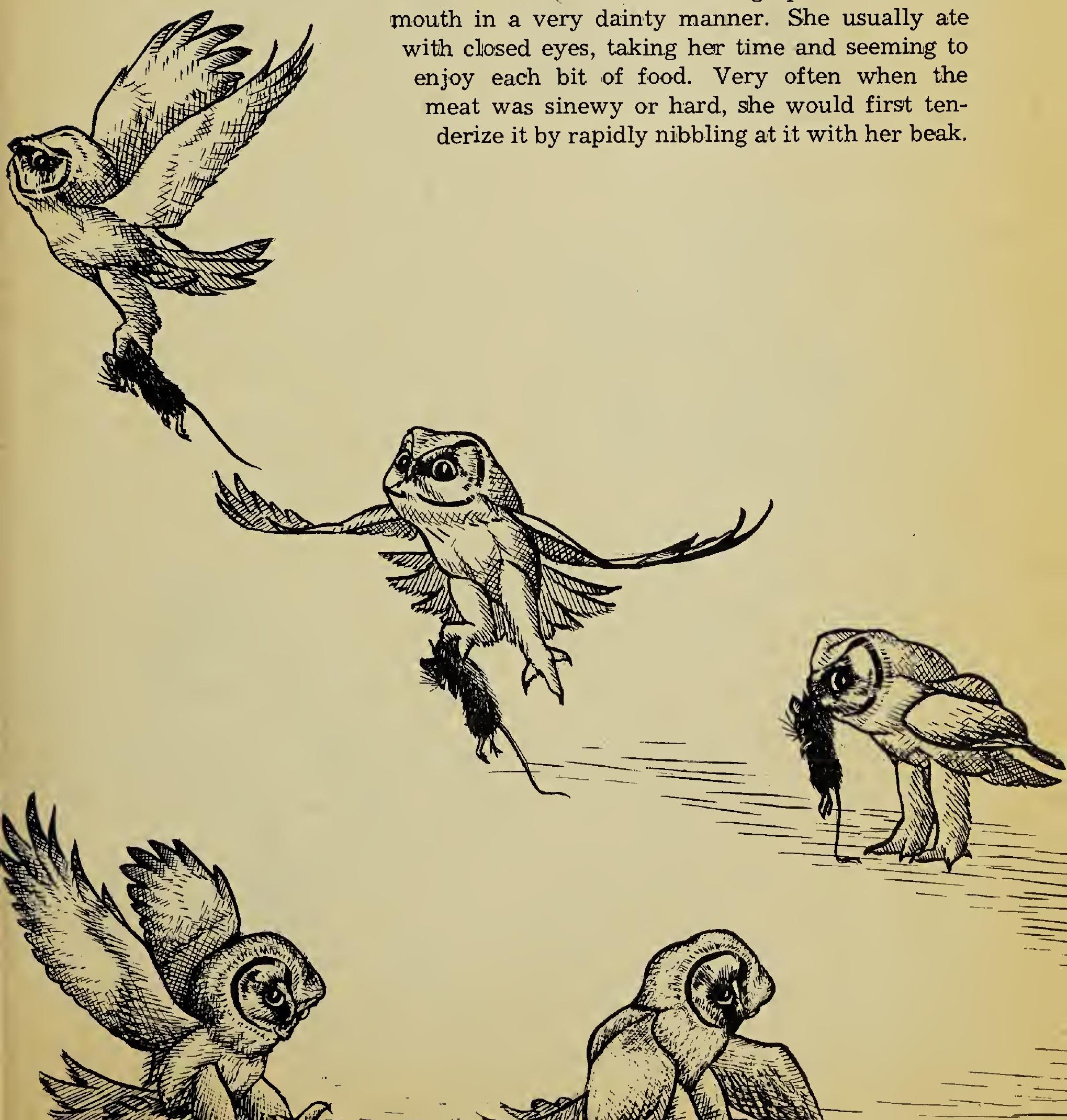

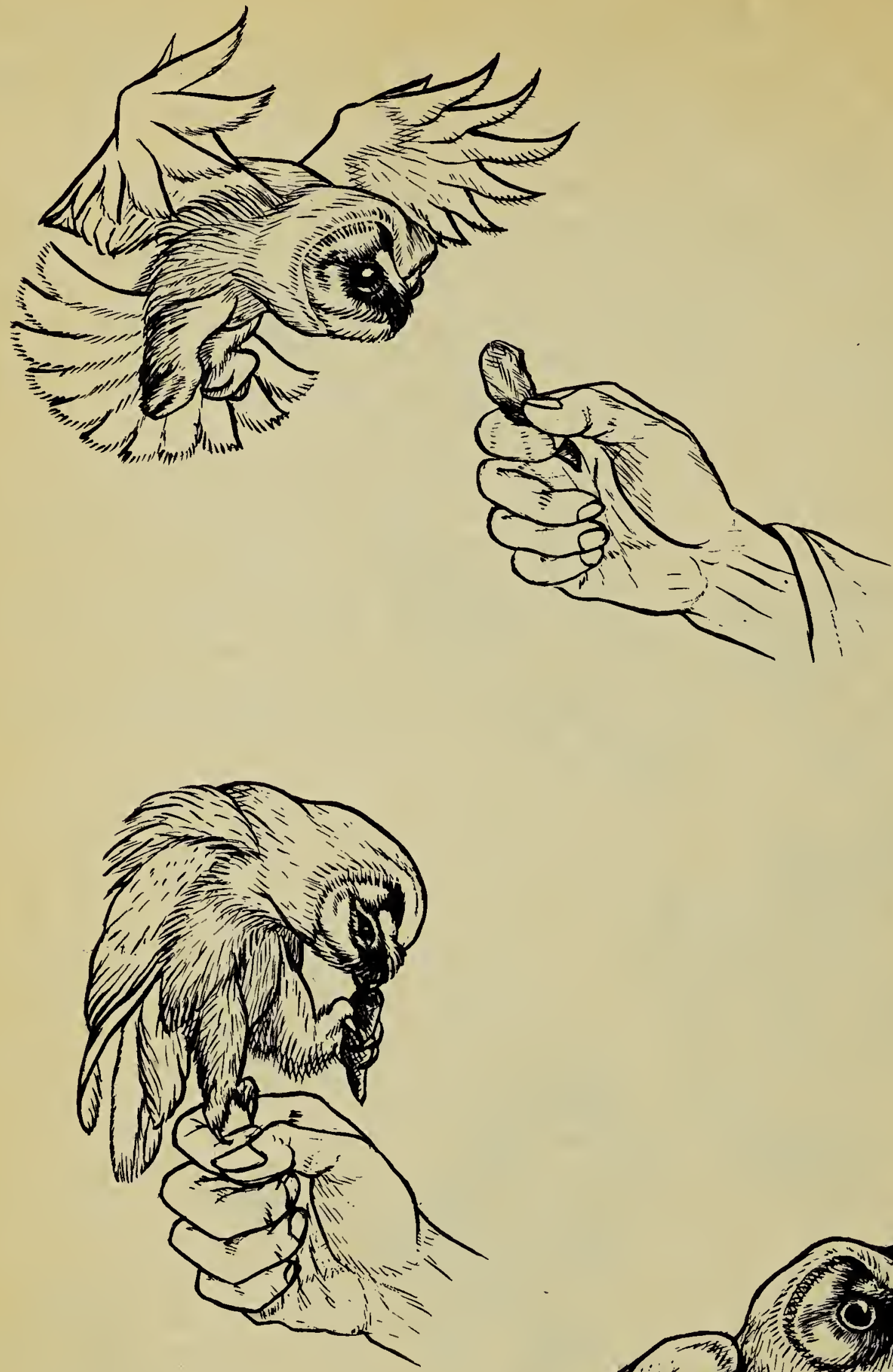

L. R. Ostofor off

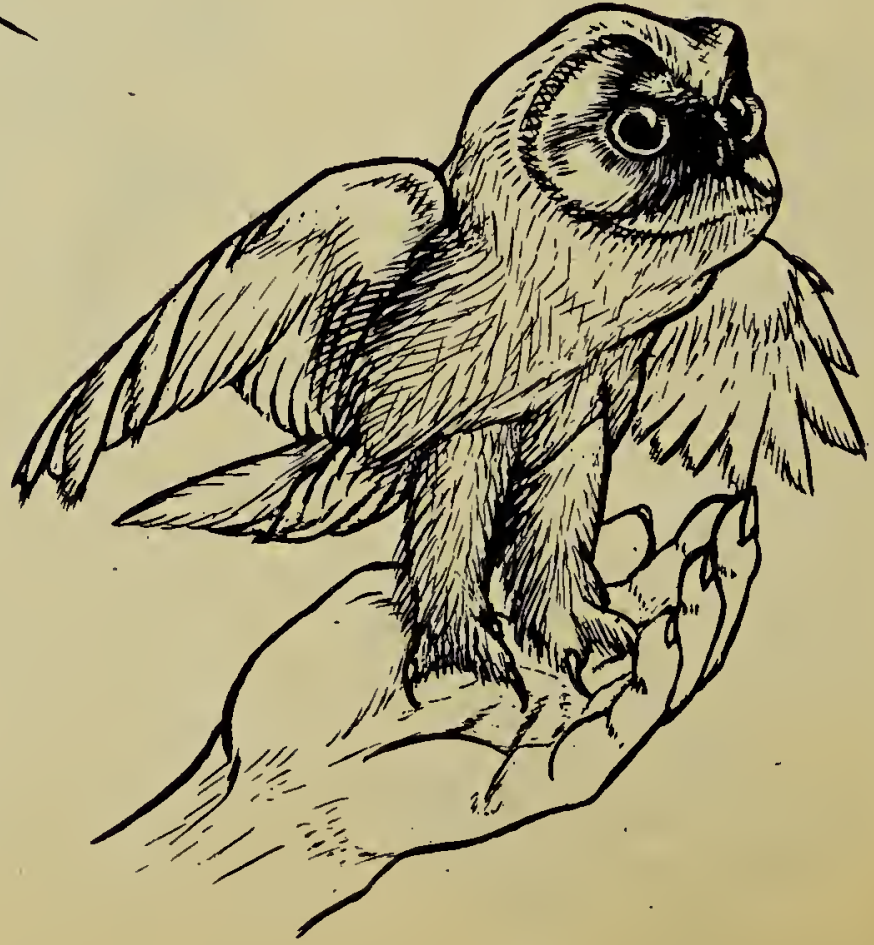

